\title{
Bifactorial Structure of Locus of Control Cross-culturally Invariant across Spain, Chile and United Kingdom*
}

\author{
Invarianza transcultural de la estructura bifactorial del locus \\ de control entre España, Chile y Reino Unido
}

\author{
Javier Suárez-Álvarez', \\ Eduardo García-Cueto ${ }^{2}$, \\ Ignacio Pedrosa ${ }^{3}$, \\ José Muñiz ${ }^{4}$ \\ University of Oviedo, Spain
}

\begin{abstract}
Locus of control (LOC) is a variable often studied owing to the important role that it plays in different contexts. Nonetheless, there is no unanimous agreement about how many dimensions make up the factorial structure of the locus of control. The goal of this research was to add new evidence of cross-cultural validity in relation to the bifactorial invariance of the LOC. The test was given to a total of 1781 participants from Spain (697), Chile (890) and The United Kingdom (194). The study of the factorial invariance between the groups was carried out using multigroup confirmatory factor analysis models for ordered-categorical data. The progressive evaluation of factorial invariance confirms that factor loadings, thresholds and error variances are invariant across groups. Relevant cross-cultural differences in LOC between Spain, Chile, and United Kingdom were not found $(P S<.50)$.

Keywords. Locus of control, cross-cultural validity, factorial invariance, Multigroup Confirmatory Factor Analysis, ordered-categorical data.

Resumen. El locus de control (LOC) es una variable frecuentemente evaluada debido a que juega un importante papel en diferentes contextos. Sin embargo, no existe un acuerdo unánime sobre cuántas dimensiones componen la estructura factorial del locus de control. El objetivo de esta investigación fue añadir nuevas evidencias de validez transcultural en relación con la invarianza bifactorial del LOC. El test fue aplicado a un total de 1781 participantes procedentes de España (697), Chile (890) y Reino Unido (194). El estudio de la invarianza factorial entre los grupos se realizó utilizando modelos de análisis factorial confirmatorio multigrupo para datos categóricamente ordenados. La evaluación progresiva de la invarianza factorial confirma que las cargas factoriales, los umbrables, y las varianzas de los errores son invariantes a través de los grupos. Finalmente, no se encontraron diferencias transculturales relevantes en LOC entre España, Chile y Reino Unido $(P S<.50)$.
\end{abstract}

Palabras clave. Locus de control, validez transcultural, invarianza factorial, Análisis Factorial Confirmatorio Multigrupo, datos categóricos.

${ }^{1}$ Javier Suárez-Álvarez. Facultad de Psicología, Universidad de Oviedo, España. Dirección Postal: Plaza Feijoo, s/n, Cabina 433003 , Oviedo, España. Email: suarezajavier@uniovi.es

${ }^{2}$ Eduardo García-Cueto: Facultad de Psicología, Universidad de Oviedo. Email: cueto@uniovi.es

${ }^{3}$ Ignacio Pedrosa: Facultad de Psicología, Universidad de Oviedo. Email: pedrosaignacio@uniovi.es

${ }^{4} J o s e ́$ Muñiz: Facultad de Psicología, Universidad de Oviedo. Email: jmuniz@uniovi.es

*Acknowledgements. This research was funded by the FPU program of the Spanish Ministry of Education, Culture and Sports and the FPI program of the Ministry of Economy and Competitiveness. References: PSI2014-56114-P, BES2012-053488, and AP2010-1999. We would like to express our utmost gratitude to the Professors Ricardo Pérez-Luco, Sonia Calvo, Pablo Livacic-Rojas, and Claudia Zúñiga (Chile), without whose collaboration this research would not have been possible.

\section{(@) $\Theta \Theta \Theta$}

Esta obra está bajo una licencia de Creative Commons Reconocimiento-NoComercial-SinObraDerivada 4.0 Internacional. 


\section{Introduction}

Locus of Control (LOC) is a variable which is frequently evaluated in psychology and education owing to the important role it plays in different contexts (Cheng, Cheung, Chio \& Chan, 2012; Muñiz, Suárez-Álvarez, Pedrosa, Fonseca-Pedrero, \& García-Cueto, 2014; Severino et al. 1966; Aiello, Cascio, Ficarra \& Messina, 2011; Suárez-Álvarez, Campillo-Álvarez, Fonseca-Pedrero, García-Cueto \& Muñiz, 2013; Urbig \& Monsen, 2012). There is no unanimous agreement on how many dimensions make up the factorial structure of LOC (Ferrando, Demestre, Anguiano-Carrasco \& Chico, 2011; Kormanik \& Rocco, 2009; Levenson, 1981; Niles, 1981; Paulhus \& Van Selst, 1990; Rotter, 1966, 1975), although the most commonly accepted theoretical models tend to reject the unidimensional structure (Levenson, 1981; Paulhus \& Van Selst, 1990; SuárezÁlvarez, Pedrosa, García-Cueto \& Muñiz, in press; Thompson \& Prendergast, 2013). In other words, the locus of control is not a continuum between two poles as originally proposed (Rotter 1966); a person may simultaneously have an external attributional style and an internal attributional style (Suárez-Álvarez et al., in press). Therefore it is reasonable to think that the cause of a behaviour may be attributed to what one does (internal LOC), while at the same time, accepting that the situation may also be influenced by events outside one's control (external LOC).

In a recent meta-analysis, Cheng, Cheung, Chio and Chan (2012) found that external LOC was not related to anxiety and depression in the same way in all cultures. That is, the significance of LOC is cultural and, hence, different depending on the population. The roots of these differences may be found in the cultural values in each society (Hofstede, 2001; Triandis \& Suh, 2002). For example, individualistic societies, such as those in the West, tend to place the responsibility on an individual for his or her actions, whereas collectivist societies, like those in Asia are generally more sensitive to external influences (Cheng et al., 2012). This might explain the fact that differences between Europeans and Americans are small whereas when comparing Americans and Asians they are much bigger (Yamaguchi, Gelfand, Ohashi \& Zemba, 2005).

Studying LOC across cultures means being able to ensure equivalence when measuring the construct (i.e. measurement invariance). Hence, if one wants to make multi-group comparisons, one has to demonstrate that the measurement instruments work in exactly the same way and that the construct under evaluation has both the same theoretical structure and psychological implications for the groups of interest (Byrne, 2008). In other words, it would not be acceptable to compare scores of people belonging to two cultural groups in a construct that did not have the same significance in both cultures. Neither would it make sense to interpret the results of a test if its application in two contexts is associated with different measurement errors (Elosua, 2005). Both questions are contingent on checking factorial invariance (Byrne, 2008; Dimitrov, 2010; Elosua \& Muñiz, 2010; Supple, Su, Plunkett, Peterson \& Bush, 2012; Zecca et al., 2012). Van de Vijver and Leung (1997) proposed three forms of factorial equivalence: configural invariance, in which the underlying psychological process is the same in the different groups since all the factors are shaped by the same items; metric invariance, in which the scaling metrics are the same; and scalar invariance, in which the origin of the scale is also the same for the different groups.

There is no unanimous agreement on the dimensionality of LOC, neither does there seem to exist any agreement on its measurement equivalence across cultures. The results are highly inconsistent. When Rotter's unidimensional scale is used, the results show a different factorial structure for Africans, Europeans and Indians (Furnham \& Henry, 1980). Smith, Trompenaars and Dugan (1995) headed a transcultural investigation in 43 countries using Rotter's scale and identified three dimensions which were relatively close to those proposed by Levenson (1981): one dimension of internality and two of externality (powerful others and chance). Other authors have also confirmed Levenson's multidimensional structure between Scots, 
Spanish and Irish (Bonetti et al., 2001), and between US and Indian groups (Ghorpade, Hattrup \& Lackritz, 1999). On the other hand, some researchers reject the equivalence of this multidimensional structure between Caucasian Americans, Filipino Americans and Latino Americans (Malcarne, Fernández \& Flores, 2005), and across young, middle-age, and elderly age groups (Shewchuk, Foelker, Camp \& Blanchard-Fields, 1992). Rossier, Dahourou and McCrae (2005) tested whether the bidimensional structure (internal and external LOC) was a better fit than the multidimensional one between Switzerland and Burkina Faso.

It is not clear if the discrepancies in these results are due to measurement problems or to cultural variations in LOC (Rossier et al., 2005). It seems as though one possible explanation might be found in the process of adapting the measuring instruments, because the process of translating an instrument from one language into another involves much more than mere back-translation (Hambleton, Merenda \& Spielberger, 2005). In addition, it must be taken into account that the main interest in transcultural studies is usually the comparison of scores according to the home country and therefore an adequate translation and adaptation of the instrument is necessary. Any bias in the translation or adaptation (Van de Vijver \& Hambleton, 1996), will directly affect the instrument's equivalence metrics and, therefore, the comparison of scores between groups (Byrne, 2008; Dimitrov, 2010).

The goal of this research was to add new evidence of validity in relation to the factorial invariance of LOC. More specifically, the research looked at the cross-cultural equivalence of the bidimensional structure of LOC (i.e. internal LOC and external LOC). In order to do this, a progressive evaluation of the factorial invariance between Spanish, Chilean and British groups was carried out using structural equation modelling (SEM) within the framework of a confirmatory factor analysis (CFA) model for ordered-categorical data. Once the cross-cultural equivalence of the measuring instrument was confirmed, a transcultural study of LOC was carried out according to home country.

\section{Method}

\section{Participants}

The sample was composed by 1781 participants of whom 39.14\% were Spanish, 49.97\% Chilean and $10.89 \%$ English (United Kingdom). The mean age of the total sample was 28.19 with a Standard Deviation of 12.73. The youngest participant was 13 and the oldest 80. More than half of the sample was female. In terms of educational attainment, $22.6 \%$ had basic secondaryschool education, $20.6 \%$ had completed high school (A-Level), $17.1 \%$ had vocational training, and 39.6\% were graduates. Descriptive statistics according to nationality are given in Table 1.

\section{Instruments}

Locus of Control Scale. In order to evaluate LOC, a scale composed of 23 items with a Likert-type 5 point scale was applied $(1=$ completely disagree, to 5 = completely agree; Suárez-Álvarez et al., in press). Of the total, 10 items evaluate internal LOC and 13 evaluate external LOC. This instrument was chosen for three fundamental reasons: a) it offers appropriate psychometric properties $\left(\alpha_{\text {internal }}=.87, \alpha_{\text {external }}=.85 ; \mathrm{CFI}\right.$ $=.90 ;$ RMSEA $=.04 ; \chi^{2} / d f=1.58$; validity evidence based on relations to other variables; Suárez-Álvarez et al., in press); b) the Likert scale overcomes the limitations of forced-choice questionnaires (Ferrando et al., 2011) and dichotomous scales (Watters, Thomas \& Streiner, 1990) and in addition, the five categories of response optimise the psychometric properties of the scales (Lozano, García-Cueto \& Muñiz, 2008); c) the test makes no reference to any specific area and is therefore able to be applied independently of any contexts of application such as educational, organisational or clinical, in such a way as to eliminate this form of contextual specificity which can make the comparison of results difficult (Wang, Bowling \& Eschleman, 2010). The data from the samples used in this work are presented in the results section.

The validation of this instrument was carried out in the Spanish population, hence it has been translated to British English using the backtranslation method following international directives 
Table 1

Description of the sample

\begin{tabular}{|c|c|c|c|c|}
\hline & $\begin{array}{l}\text { Spain } \\
(N=697)\end{array}$ & $\begin{array}{l}\text { Chile } \\
(N=890)\end{array}$ & $\begin{array}{l}\mathrm{UK} \\
(\mathrm{N}=194)\end{array}$ & $\begin{array}{l}\text { Total } \\
(N=1781)\end{array}$ \\
\hline \multicolumn{5}{|l|}{ Sex } \\
\hline Male $(\%)$ & 42.6 & 48.1 & 38.7 & 44.9 \\
\hline Female $(\%)$ & 57.4 & 51.9 & 61.3 & 55.1 \\
\hline \multicolumn{5}{|l|}{ Age } \\
\hline Mean age (SD) & $22.46(9.22)$ & $29.38(11.58)$ & $42.87(15.00)$ & $28.19(12.73)$ \\
\hline Age range & $13-63$ & $13-80$ & $14-79$ & $13-80$ \\
\hline \multicolumn{5}{|l|}{ Studies completed } \\
\hline Secondary School & 15.2 & 32.6 & 3.6 & 22.6 \\
\hline High School & 37.1 & 7.6 & 21.1 & 20.6 \\
\hline $\begin{array}{c}\text { Vocational } \\
\text { training }\end{array}$ & 14.7 & 22.4 & 2.1 & 17.1 \\
\hline University & 33.0 & 37.4 & 73.2 & 39.7 \\
\hline
\end{tabular}

for translation and adaptation of tests (Hambleton, Merenda, \& Spielberger, 2005; Muñiz \& Bartram, 2007; Muñiz, Elosua, \& Hambleton, 2013). Firstly, an independent translation of the test was obtained from an experienced native translator. Once this translation was done, all the items were checked by a group of experts who produced a first draft of the test by consensus. Following the production of this first draft in Spanish, a different experienced translator produced a back-translation into English. Then, a group of experts with experience in translating psychometric tests evaluated the level of semantic correspondence between the original version of the test and the back-translation.

\section{Procedure}

The questionnaire was applied using paperand-pencil $(n=399)$ and web online answer format $(n=1382)$. The measurement equivalent across the form of application (paper-andpencil or web-based) was previously confirmed (Suárez-Álvarez et al., in press). Participants were informed that their responses were confidential and anonymous, and participation was totally voluntary. The participants did not receive any type of compensation for their participation. The Ethics Committee of the Faculty of Psychology in the University of Oviedo gave their approval for this research to be carried out.

\section{Data analysis}

Firstly, an analysis of the items was carried out separately for internal LOC and external LOC. This was done by calculating the discrimination index for each dimension. Then, the ordinal reliability coefficient was calculated for Likerttype scales (Elosua \& Zumbo, 2008). Factorial invariance between the groups was analysed using multigroup confirmatory factor analysis (MG-CFA) for ordered-categorical data within the framework of structural equation modeling (Byrne, 2008; Dimitrov, 2010). Firstly, a check was made that the proposed structure (which items measure which feature) initially suited each group separately (i.e. configural invariance). A Single Group CFA (Abad, Olea, Ponsoda \& García, 2011; Muthén \& Muthén, 2010) was fit to each group. 
Following that, several nested models of MGCFA were performed to study the factor loadings invariance (i.e. Model 1), thresholds invariance (i.e. Model 2), and error variances and factor variances are equal across groups (i.e. Model 3), according to the models proposed by Muthén and Asparouhov (2002), and Muthén and Muthén (2010). A robust weighted least squares estimator (WLSMV) was used, indicated for categorically ordered data (Elosua, 2010; Koh \& Zumbo, 2008; Muthén \& Asparouhov, 2002).

The following criteria were used for the progressive evaluation of factorial invariance: chisquare differences using DIFFTEST correction (Muthén \& Muthén, 2010), the difference between the values of Bentler's comparative fit index (CFI; Cheung \& Rensvold, 2002), a comparison of confidence intervals of the Root Mean Square Error of Approximation (RMSEA; Byrne, 2008; Elosua \& Muñiz, 2010). Finally, the ShapiroWilk test was used to study normality (Pedrosa, Juarros-Basterretxea, Robles-Fernández, Basteiro y García-Cueto, 2015) and the Kruskal-Wallis test was used to study transcultural differences. For the non-parametric multiple comparisons, Gibbons' (1993) proposed formula based on the Bonferroni correction was used. The estimation of effect size for non-parametric tests was done using Probability of Superiority (PS; Grissom \& Kim, 2011).

\section{Results}

\section{Preliminary Analysis}

First of all, the items of each dimension with discrimination indices below .25 were removed (Muñiz, Fidalgo, García-Cueto, Martínez \& Moreno, 2005). Using this criterion led to the elimination of item 7 - To be successful it is necessary to have good contacts-. Once this item had been eliminated from the test, the discrimination indices for the external locus of control sub-scale ranged from .31-.54 (Spain), .31-.61 (Chile), and .33-.63 (UK). For the internal locus of control sub-scale the discrimination indices were between .26 and .61 (Spain), between .47 and .72 (Chile), and between .43 and .82 (UK).

On the other hand, the estimation of the reliability coefficient for ordinal data via Cronbach's alpha gave acceptably consistent values from the groups both for internal LOC $\left(\alpha_{\text {Spain }}=.81 ; \alpha_{\text {Chile }}=.96 ; \alpha_{\mathrm{UK}}=.93\right)$ and external LOC $\left(\alpha_{\text {Spain }}=.82 ; \alpha_{\text {Chile }}=.93 ; \alpha_{\mathrm{UK}}=.88\right)$.

\section{Configural Invariance}

Table 2 shows the CFA fit indices done in each group (Single CFA). The value of $\chi^{2 / d f}$ is lower than 5 , the CFI is larger than .90, and the RMSEA is less than .08 .

\section{Progressive evaluation of factorial invariance}

The progressive evaluation of factorial invariance starts with configural invariance as a base model

Table 2

Single Confirmatory Factor Analysis for each group

\begin{tabular}{|c|c|c|c|c|}
\hline Model & $\chi^{2}(d f)$ & $\chi^{2} / D F$ & CFI & $\operatorname{RMSEA}(\mathrm{CI})$ \\
\hline Spain & $726.06(202)$ & 3.59 & .905 & $\begin{array}{l}.062 \\
(.057-.067)\end{array}$ \\
\hline Chile & $957.39(202)$ & 4.74 & .975 & $\begin{array}{l}.065 \\
(.061-.069)\end{array}$ \\
\hline UK & $323.50(202)$ & 1.60 & .960 & $\begin{array}{l}.057 \\
(.045-.068)\end{array}$ \\
\hline
\end{tabular}

Note. $\chi^{2}=$ chi-square fit statistic under robust weighted least square estimation; $d f=$ degrees of freedom; CFI $=$ comparative fit index; RMSEA = root mean square error of approximation; CI = confidence interval. 
Table 3

Progressive factorial invariance analysis

\begin{tabular}{|c|c|c|c|c|}
\hline Model & $\chi^{2}(d f)$ & $\Delta \chi^{2}(d f)$ & CFI & RMSEA(CI) \\
\hline 0 . Unconstrained model & $2732.124(694)$ & & .952 & $\begin{array}{l}.070 \\
(.068-.073)\end{array}$ \\
\hline $\begin{array}{l}\text { 1. Factor loadings invariance } \\
\text { model }\end{array}$ & $2800.211(734)$ & $\begin{array}{l}184.949(40) \\
p<.001 *\end{array}$ & .952 & $\begin{array}{l}.069 \\
(.066-.072)\end{array}$ \\
\hline $\begin{array}{l}\text { 2. Factor loadings and } \\
\text { thresholds invariance model }\end{array}$ & $2985.411(774)$ & $\begin{array}{l}155.002(40) \\
p<.001 *\end{array}$ & .948 & $\begin{array}{l}.069 \\
(.067-.072)\end{array}$ \\
\hline $\begin{array}{l}\text { 3. Factor loadings, thresholds, } \\
\text { and error variances and factor } \\
\text { variances }\end{array}$ & $3348.136(818)$ & $\begin{array}{l}443.353(44) \\
p<.001 *\end{array}$ & .941 & $\begin{array}{l}.072 \\
(.070-.075)\end{array}$ \\
\hline
\end{tabular}

Note. $\chi^{2}=$ chi-square fit statistic under robust weighted least square estimation; $d f=$ degrees of freedom; $\Delta \chi^{2}=$ DIFFTEST for chi-square difference; $\mathrm{CFI}=$ comparative fit index; RMSEA = root mean square error of approximation; $\mathrm{CI}=$ confidence interval.

*Factorial invariance would be rejected.

(Model 0; Unconstrained multi-group model). As can be seen in Table 3, according to the global fit indices, it seems sensible to accept the equivalence of the base model between the groups.

Next, an additional model is used in which metric invariance is assumed (Model 1; Factor loadings invariance). In order to be able to accept this second model the $\chi^{2}$ difference between the two models (Model 0 - Model 1) must not be statistically significant (Muthén \& Muthén, 2010; Satorra \& Bentler, 2001). In this case (Table 3), the $\chi^{2}$ difference between the models is statistically significant $(\phi<.001)$. Nonetheless, various authors (Byrne, 2008; Cheung \& Rensvold, 2002) have argued that $\chi^{2}$ is an impractical and unrealistic basis for evidence of equivalence. For this reason multiple decision criteria were used: the difference between the CFIs of the two models is less than $.01\left(\mathrm{CFI}_{\bmod 0-\bmod 1}=.0001\right)$ and there were no statistically significant differences (CI $=90 \%$ ) in the RMSEA of both models. According to these criteria, it seems sensible to accept the hypothesis that factor loadings are equal across groups.
The next nested model (Model 2; Factor loading and thresholds invariance) looks at invariance in measurement structures, and estimates the threshold for each indicator. For this reason, the model uses thresholds values as fixed parameters. It should be noted that thresholds are estimated for categorical indicators instead of intercepts which are for continuous indicators (Elosua, 2010; Koh \& Zumbo, 2008; Muthén \& Asparouhov, 2002). As can be seen in Table 3, there are no statistically significant differences (CI $=90 \%)$ between the RMSEA of both models (Model 2 - Model 1) and the difference between the Bentler comparative indices is lower .01 (CFI ${ }_{\text {mod1-mod2 }}$ $=.004)$. According to these criteria Factor loadings and thresholds are invariant across groups.

Multiple group analysis can be done for categorical variables as long as thresholds and scale factors are included in the model. The scale factors consider possible differences in variances across groups. Hence, in the next step the scale factors are fixed to be equal across groups (Model 3). It implies that 
factor loadings, factor variances and the residual variances are invariant across groups. Therefore, holding scale factors equal across groups has a strong implication (Muthén \& Muthén, 2010). As observed in Table 3, this model has an acceptable fit: the difference between the CFIs of the two models is lower than $.01\left(\mathrm{CFI}_{\bmod 2-\bmod 3}=.007\right)$, and there are no statistically significant differences (CI $=90 \%$ ) between the RMSEA of both models.

\section{Study of cross-cultural differences}

The Shapiro-Wilk test for the study of normality was statistically significant $(p<.001)$ for both subscales, so the Kruskal-Wallis test was used for the study of the differences as a function of nationality. As can be seen in Table 4, there are statistically significant differences $(p<.05)$ in both subscales by nationality between groups. Furthermore, a posteriori tests (Gibbons, 1993) showed that there were statistically significant differences $(\phi<.05)$ between Spain and the others groups, but not between UK and Chile ( $p>$.05). Pairwise comparison shows that participants from Spain scored higher in internal LOC than British $(p<.001 ; P S=.39)$, and Chilean $(p=.003$; PS $=.45)$. On the contrary, the Spanish scored lower for external LOC than British $(p=.001 ;$ PS $=.42)$, and Chilean $(p=.015$; PS $=$ .46). Nevertheless, it must be borne in mind that the effect sizes in all pairwise comparisons were not high enough to consider relevant or large the differences found $(P S<.50)$.

\section{Discussion and conclusions}

The objective of this research was to add new evidence of cross-cultural validity in relation to factorial invariance of LOC. Cross-cultural equivalence of the instrument was carried out following the steps established by Byrne (2008): a) translation and adaptation of a test for a British population to evaluate LOC (Oviedo Locus of Control Scale; Suárez-Álvarez et al., in press) using the back-translation method and following international directives for the translation and adaptation of psychometric instruments (Hambleton, Merenda, \& Spielberger, 2005; Muñiz \& Bartram, 2007; Muñiz et al., 2013); b) checking that the original factorial structure of the instrument is the same in the new versions and c) checking the equivalence of the changes across groups.

Firstly, regarding the translation and adaptation of the instrument, one item was found to have low discriminative power in the British population (To be successful it is necessary to have good contacts). However, this item had a value of .31 in the the Spanish and .35 in the Chilean sample. This suggests that the lack of discriminative power for the British could be due to a problem with the translation (Muñiz et al., 2013). Spanish speakers interpret this item in a way which clearly corresponds to an external attributional style; it seems reasonable to think that the British do not consider having "good contacts" as an external or chance event, but instead more as a consequence of personal merit. This fact highlights the importance and complexity of adapting instruments to other cultures (Hambleton,

Table 4

Comparison of rank means with Kruskal-Wallis Test of each subscale as a function of nationality

\begin{tabular}{lllllll}
\hline \multirow{2}{*}{ Subscales } & Spain & Chile & UK & \multirow{2}{*}{$\chi^{2}(d f)$} & $p$ & Post-hoc test \\
& Rank mean & Rank mean & Rank mean & & & \\
\hline Internal LOC & 951.40 & 867.54 & 781.62 & $20.30(2)$ & $p<.001$ & Spain > Chile,UK* \\
External LOC & 847.96 & 906.06 & 976.56 & $11.03(2)$ & $p=.004$ & UK, Chile > Spain* \\
\hline
\end{tabular}

Note. $\chi^{2}=$ chi-square test; $d f=$ degrees of freedom.

*The differences were statistically significant $(p<.05)$ between groups. 
Merenda, \& Spielberger, 2005). On the other hand, the reliability coefficients were acceptable in all groups for both the internal LOC $\left(\alpha_{\text {Spain }}=.81 ; \alpha_{\text {Chile }}=.96 ; \alpha_{\text {UK }}\right.$ $=.93)$ and external LOC $\left(\alpha_{\text {Spain }}=.82 ; \alpha_{\text {Chile }}=.93 ; \alpha_{\mathrm{UK}}=\right.$ .88). Furthermore, these results reasonably approximate those obtained in the original test $\left(\alpha_{\text {internal }}=.87 ; \alpha_{\text {external }}=\right.$ $.85)$.

Secondly, the configural invariance of the instrument was confirmed in all three groups. Hence it is reasonable to conclude that the bidimensional structure is confirmed in the Spanish, Chilean and British populations. Hence it can be concluded that the original factorial structure of the instrument is the same in the new versions.

Thirdly, a strong measurement invariance assumption was confirmed by the progressive factorial invariance analysis (Table 3). This means that not only factor loadings and thresholds are invariant across Spain, Chile, and United Kingdom, if not that error variances and factor variances are invariant too. This implies that similar levels of precision are performed when the construct is measured across these groups.

Finally, there were statistically significant differences between the nationalities in both subscales $(p<.001)$. As can be seen in Table 4, the British and Chileans had the highest score in external LOC and the lowest in internal LOC, while this was the inverse in the case of the Spanish. These results coincide with the general tendency to observe differences in LOC according to nationality (Cheng et al., 2012; Malcarne, Fernández \& Flores, 2005; Rossier, Dahourou, \& McCrae, 2005; Yamaguchi, Gelfand, Ohashi \& Zemba, 2005). On the other hand, it seems reasonable that, nowadays, people from changing economies such as Spain tend to make internal attributions to a greater extent than those from more well off countries such as Britain. The reason is that people might be expected to attribute the cause of change to what one can do. On the contrary, in countries with a social welfare system and a better economy one would expect that the inhabitants would tend to trust in community or welfare systems for support. Furthermore, the differences between Spanish and
Chileans were smaller in both constructs than when they were compared with British. Interestingly, Chile and Spain have similar scores for power distance, uncertainty avoidance, and individualism (Hofstede, 2001). Regardless, the effect size was considerably low implying that the differences found are not relevant. In sum, the differences found must be taken as a tendency, and if it wants to support crosscultural differences, more empirical evidence should be provided.

In summary, the progressive evaluation of factorial invariance allows us to confirm a strong measurement invariance assumption. This provides evidence that the items were measured with the same precision in each group, so the group differences on any item are due only to group differences on the common factors (Dimitrov, 2010). These results add new evidence for the theses that a bidimensional structure represents the most realistic form of LOC in cross-cultural studies (Rossier et al., 2005).

The following limitations must be borne in mind when interpreting these results. Firstly, it would be useful to increase the sample size to improve the representativeness of the data. Secondly, it would be interesting to have convergent measures with LOC at transcultural level to improve the evidence of validity. Lastly, all the data were collected via self-reporting methods; in the future, it would be useful to administer other measuring instruments such as interviews or situational tests.

\section{References}

Abad, F. J., Olea, J., Ponsoda, V., \& García, C. (2011). Medición en ciencias sociales y de la salud [Measurement in the social and health sciences]. Madrid: Síntesis.

Anie, K. A., Dasgupta, T., Ezenduka, P., Anarado, A., \& Emodi, I. (2007). A cross-cultural study of psychosocial aspects of sickle cell disease in the UK and Nigeria. Psychology, Health \& Medicine, 12(3), 299304. doi: 10.1080/13548500600984034

Bonetti, D., Johnston, M., Rodríguez-Marin, J., Pastor, M., Martin-Aragon, M., Doherty, E., \& Sheehan, K. 
(2001). Dimensions of perceived control: A factor analysis of three measures and an examination of their relation to activity level and mood in a student and cross-cultural patient simple. Psychology \& Health, 16(1), 655-674. doi: 10.1080/08870440108405865

Byrne, B. M. (2001). Structural equation modeling with AMOS. Mahwah, NJ: Lawrence Erlbaum Associates.

Byrne, B. M. (2008). Testing for multigroup equivalence of a measuring instrument: A walk through the process. Psicothema, 20(4), 872-882.

Byrne, B. M., \& Watkins, D. (2003). The issue of measurement invariance revisited. Journal of Cross-Cultural Research, 34(2), 155-175. doi: 10.1177/0022022102250225

Cheng, C., Cheung, S.F., Chio, J.H., \& Chan, M.P (2012). Cultural meaning of perceived control: A meta-analysis of locus of control and psychological symptoms across 18 cultural regions. Psychological Bulletin, 39(1), 152-88. doi:10.1037/a0028596

Cheung, G.W., \& Rensvold, R.B. (2002). Evaluating goodness-of-fit indexes for testing measurement invariance. Structural Equation Modeling, 9, 233-255.

Dimitrov, D. M. (2010). Testing for factorial invariance in the context of construct validation. Measurement and Evaluation in Counseling and Development, 43(2), 121-149. doi: 10.1177/0748175610373459

Elosua, P. (2005). Progressive way in strict factorial invariance. Psicothema, 17(2), 356-362.

Elosua, P. (2010). Assessing measurement equivalence in ordered-categorical data. Psicológica, 32, 403-421.

Elosua, P., \& Muñiz, J. (2010). Exploring the factorial structure of the self-concept. European Psychologist, 15(1), 58-67. doi: 10.1027/1016-9040/a000006

Elosua, P., \& Zumbo, B. D. (2008). Reliability coefficients for ordinal response scales. Psicothema, 20(4), 896-901.

Ferrando, P. J., Demestre, J., Anguiano-Carrasco, C., \& Chico, E. (2011). An IRT assessment of Rotter I-E scale: A new approach and some considerations. Psicothema, 23(2), 282-288.

Furmham, A., \& Henry, J. (1980). Cross-cultural locus of control studies: Experiment and critique. Psychological Reports, 47(1), 23-29.

Ghorpade, J., Hattrup, K., \& Lackritz, J. R. (1999). The use of personality measures in cross-cultural research: A test of three personality scales across two countries. Journal of Applied Psychology, 84(5), 670-679.

Gibbons, J. D. (1993) Nomparametric statistics: An introduction. Newbury Park, CA: Sage University Paper.

Grissom, R.J., \& Kim, J.J. (2011). Effect Sizes for Research: Univariate and Multivariate Applications, Second Edition. New York, NY: Routledge.

Hambleton, R., Merenda, P., \& Spielberger, C. (2005). Adapting educational and psychological tests for crosscultural assessment. Mahwah, NJ: Erlbaum.

Hofstede, G. H. (2001). Culture's consequences: Comparing values, behaviors, institutions, and organizations across nations (2nd ed.). Thousand Oaks, CA: Sage.

Hu, L.T., \& Bentler, P. M. (1999). Cut off criteria for fit indexes in covariance structure analysis: Conventional criteria versus new alternatives. Structural Equation Modeling, 6, 1-55.

Koh, K.H., \& Zumbo, B. (2008). Multi-Group Confirmatory Factor Analysis for testing measurement invariance in mixed item format data. Journal of Modern Applied Statistical Methods, 7(2), 471-477.

Kormanik, M. B., \& Rocco, T. S. (2009). Internal versus external control of reinforcement: A review of the locus of control construct. Human Resource Development Review, 8(4), 463-483. doi: http:/ / dx.doi. org/10.1177/1534484309342080

Levenson, H. (1981). Differentiating among internality, powerful others, and chance. In H. M. Lefcourt (Ed.), Research with the locus of control construct (vol. 1, pp. 15-63). New York, NY: Academic. 
Lozano, L.M., García-Cueto, E., \& Muñiz, J. (2008). Effect of the number of response categories on the reliability and validity of rating scales. Methodology, 4(2), 73-79. http://dx.doi.org/10.1027/16142241.4.2.73

Malcarne, V. L., Fernández, S., \& Flores, L. (2005). Factorial validity of the multidimensional health locus of control scales for three American ethnic groups. Journal of Health Psychology, 10(5), 657-667.

Muñiz, J., \& Bartram, D. (2007). Improving international tests and testing. European Psychologist, 12, 206-219. http://dx.doi.org/10.1027/1016-9040.12.3.206

Muñiz, J., Fidalgo, A.M., García-Cueto, E., Martínez, R., \& Moreno, R. (2005). Análisis de los items [Item analysis]. Madrid: La muralla.

Muñiz, J., Elosua, P., \& Hambleton, R. K. (2013). International Test Commission Guidelines for test translation and adaptation: Second edition. Psicothema, 25(2), 151-157.

Muñiz, J., Suárez-Álvarez, J., Pedrosa, I., FonsecaPedrero, E., \& García-Cueto, E. (2014). Enterprising personality profile in youth: Components and assessment. Psicothema, 26(4), 545-553. doi: 10.7334/ psicothema2014.182

Muthén, B. O. and Asparouhov, T. (2002). Latent variable analysis with categorical outcomes: Multiple-group and growth modeling in Mplus. Mplus Web Notes: No. 4. Retrieved from: www.statmodel.com.

Muthén, L.K., \& Muthén, B.O. (2010). Mplus User's Guide. Sixth Edition. Los Angeles, CA: Muthén \& Muthén. Retrieved from: http://www.statmodel. com/download/usersguide/Mplus $\% 20$ Users $\% 20$ Guide\%20v6.pdf

Niles, F. S. (1981). Dimensionality of Rotter's I-E scale in Sri Lanka. Journal of Cross-Cultural Psychology, 12(4), 473-479.

Paulhus, D. L., \& Van Selst, M. (1990). The spheres of control scale: 10 years of research. Personality and Individual Differences, 11, 1029-1036. doi:10.1016/0191-8869(90)90130-J
Pedrosa, I., Juarros-Basterretxea, J., Robles-Fernández, A., Basteiro, J. y García-Cueto, E. (2015). Goodness of Fit Tests for Symmetric Distributions, which Statistical Should I Use? Universitas Psychologica, 14(1), 15-24.

Rossier, J., Dahourou, D., \& McCrae, R. R. (2005). Structural and mean level analysis of the five factor model and locus of control: Further evidence from Africa. Journal of Cross-Cultural Psychology, 36(2), 227-246. doi: 10.1177/0022022104272903

Rotter, J. B. (1966). Generalized expectancies for internal versus external control of reinforcement. Psychological Monographs, 80(1), 1-28. http://dx.doi. org/10.1037/h0092976

Rotter,J. B. (1975). Some problems and misconceptions related to the construct of internal versus external control of reinforcement. Journal of Consulting and Clinical Psychology, 43(1), 56-67. http://dx.doi. org/10.1037/h0076301

Satorra, A., \& Bentler, P. M. (2001). A scaled difference chi-square test statistic for moment structure analysis. Psychometrika, 66, 507-514.

Severino, S., Aiello, F., Cascio, M., Ficarra, L., \& Messina, R. (2011). Distance education: The role of self-efficacy and locus of control in lifelong learning. Procedia: Social and Behavioral Sciences, 28, 705-717. doi:10.1016/j.sbspro.2011.11.132

Shewchuk, R. M., Foelker, G. A., Camp, C. J., \& Blanchard-Fields, F. (1992). Factorial invariance issues in the study of adult personality: An example using Levenson's locus of control scale. Experimental Aging Research, 18(2), 15-24.

Smith, P. B., Trompenaars, F., \& Dugan, S. (1995). The Rotter locus of control scale in 43 countries: A test of cultural relativity. International Journal of Psychology, 30, 377-400.

Suárez-Álvarez, J., Campillo-Álvarez, A., FonsecaPedrero, E., García-Cueto, E., \& Muñiz, J. (2013). Professional training in the workplace: The role of achievement motivation and locus of control. The Spanish Journal of Psychology, 16, E35. doi: http:// dx.doi.org/10.1017/sjp.2013.19 
Suárez-Álvarez, J., Pedrosa, I., García-Cueto, E., \& Muñiz, J. (in press). New validity evidence support Locus of Control bi-dimensionality. Anales de Psicología.

Supple, A. J., Su, J., Plunkett, S. W., Peterson, G. W., \& Bush, K. R. (2012). Factor Structure of the Rosenberg Self-Esteem Scale. Journal of Cross-Cultural Psychology, 44(5), 748-764. doi: 10.1177/0022022112468942

Thompson, E. R., \& Prendergast, G. P. (2013). Belief in luck and luckiness: Conceptual clarification and new measure validation. Personality and Individual Differences, 54, 501-506. doi: http://dx.doi. org/10.1016/j.paid.2012.10.027

Triandis, H. C. (2001). Individualism and collectivism: Past, present, and future. In D. Matsumoto (Ed.), The handbook of culture and psychology (pp. 35-50). New York, NY: Oxford University.

Urbig, D., \& Monsen, E. (2012). The structure of optimism: Controllability affects the extent to which efficacy beliefs shape outcome expectancies. Journal of Economic Psychology, 33, 854-867. http:// dx.doi.org/10.1016/j.joep.2012.03.004.

Van de Vijver, F., \& Hambleton, R. K. (1996). Translating tests: Some practical guidelines. American Psychologist, 1(2), 85.
Van de Vijver, F.J.R., \& Leung, K. (1997). Methods and data analysis for cross-cultural research. Newbury Park, CA: Sage.

Wang, Q., Bowling, N.A., \& Eschleman, K.J. (2010). A meta-analytic examination of work and general locus of control. Journal of Applied Psychology, 95(4), 761-768. http://dx.doi.org/10.1037/a0017707

Watters, D. A., Thomas, B. H., \& Streiner, D. L. (1990). Factor analysis of the Nowicki-Strickland locus of control scale: Why is replication so difficult? Educational and Psychological Measurement, 50(3), 515523. doi: 10.1177/0013164490503005.

Yamaguchi, S., Gelfand, M., Ohashi, M. M., \& Zemba, Y. (2005). The cultural psychology of control: Illusions of personal versus collective control in the United States and Japan. Journal of Cross-Cultural Psychology, 36(6), 750-761. doi: 10.1177/0022022105280513

Zecca, G., Verardi, S., Antonietti, J.P., Dahourou, D., Adjahouisso, M., Ah-Kion, J., ... \& Rossier, J. (2012). African cultures and the five-factor model of personality: Evidence for a specific pan-african structure and profile? Journal of Cross-Cultural Psychology, 44(5), 684-700. doi: 10.1177/0022022112468943

Received: May 20 ${ }^{\text {th }}, 2015$ Accepted: September 15 $5^{\text {th }}, 2015$ 